\title{
THE OPTIMAL TAXATION OF FOREIGN SOURCE INVESTMENT INCOME*
}

\author{
Martin Feldstein AND David HaRTMan
}

I. The basic model, 615.-II. Tax rate interdependence, 620.-III. Foreign borrowing, 626. - IV. Conclusion, 628.

Direct foreign investment is of growing importance throughout the world. Taxation of the resulting investment income is therefore a significant problem for both the host country in which the investment is made and the home country from which the capital comes. In the present paper we derive optimal tax rules for both the capital-exporting and capital-importing countries. Of particular interest to a large capital exporter like the United States is the derivation of the tax rate that is optimal for the capital-exporting nation when other countries adjust their tax rates in response. ${ }^{1}$

Our paper begins with the relatively simple problem of optimal taxation as viewed by the capital-exporting ("home") country when it can assume that its actions do not alter the tax rate in the host country. As a further simplification, the only foreign investment is the transfer of equity capital from the home country to the host country. We assume that such direct investment occurs because the "subsidiary firms" (i.e., the firms owned by residents of the home country that produce in the host country) have a different production technology than what is available to host country firms. For an important special case of this problem, i.e., when foreign investment accounts for only a very small fraction of host country production, we obtain an optimal tax rule that corresponds to a common policy prescription: the capital-exporting country should tax foreign source profits after foreign tax at the same rate that it taxes domestic profits. This "full taxation after deduction" rule is a useful benchmark against which to compare the optimal tax policies in more general cases. For example, Section I also shows that when foreign investment accounts for a significant fraction of production in the host country, the capital-exporting country should tax foreign source investment income

* We are grateful to the National Science Foundation for support of this research and to Richard Caves, Thomas Horst, Peggy Musgrave, David Lipton, members of the Harvard Public Finance Seminar, and an anonymous reviewer for useful comments.

1. Earlier contributions on the taxation of foreign investment income include Krause and Dam [1964], Musgrave [1969, 1975], Richman [1963], Jones [1967], Kemp [1962], MacDougall [1960], Hufbauer [1975], Hamada [1966], and Horst [1977]. 
more heavily than is implied by the "full taxation after deduction" rule.

The important question of tax rate interdependence is developed in Section II. We assume that the host countries are small relative to the capital-exporting country. They therefore regard the tax rates in the capital-exporting country as fixed parameters and choose their own tax rate on foreign investment to be optimal, conditional on the tax rates in the capital-exporting country. ${ }^{2}$ The optimal tax policy of the capital-exporting country must take this reaction by the host countries into account. ${ }^{3}$

We began our analysis of this problem with the expectation that allowing for such tax rate interdependence would lower the home country's optimal tax on foreign source investment income. We reasoned that a lower tax rate in the capital-exporting country would make home country firms more sensitive to the foreign tax rate ${ }^{4}$ and that this in turn would induce foreign countries to cut their tax rates in order to attract foreign investment. By this line of reasoning, reducing the taxation of foreign source investment income would be a net benefit to the home country because subsidiary firms would pay a smaller fraction of their income in host country taxes.

Our initial expectations turned out to be false. Under quite general conditions, it is optimal for the host country to tax foreign source investment more heavily than the "full taxation after deduction" rule suggests. By raising its tax rate, the home country can reduce the tax rate levied by the host country. This allowance for interdependence does make it worthwhile for the home country to use its tax rates to induce a lower rate of tax by host countries, but this entails a heavier rather than a lighter tax by the home country.

In the third section we replace the assumption that all foreign investment is financed by a transfer of equity capital from the home country with the more realistic description that subsidiary firms borrow in the host country. We assume realistically that an increase in equity investment is accompanied by increased borrowing and that the rate of interest is less than the marginal product of investment

2. We treat the host countries as effectively identical so that, from the point of view of the capital-exporting country, the host countries are equivalent to a single country, and all choose the same policy. It is important, however, that there are in fact a large number of such countries so that they take the capital-exporting country's tax rates as parameters.

3 . Note that in the process of deriving the optimal policy for the capital-exporting country, we obtain as a by-product the optimal tax policy of the small, capital-importing country.

4. In the extreme, a 100 percent tax rate by the home country on subsidiary profits net of tax makes home country firms completely insensitive to the host's tax rate. 
in the subsidiary firms. Although this raises the profitability to the home country of investment by its foreign subsidiaries, we show that this need not alter the conclusions of the previous sections.

We regard the present paper as only a first step in a proper analysis of the complex issue of optimal taxation of foreign source investment income. A more complete analysis would reflect the interdependence of trade and investment, ${ }^{5}$ the existence of portfolio investment as well as direct investment, the multinational character of the firms' investment and financing decisions, and the several factors that account for the simultaneous two-way flow of investment between individual pairs of countries. The static analysis of the present paper should be extended to consider investment paths in growing economics. Finally, the purely nationalistic optimality criterion could be generalized to give some weight to the real income of the rest of the world.

\section{THE BASIC MODEL}

This section sets out the basic model that will be developed and analyzes the special case of optimal taxation when the subsidiary firm borrows no capital in the host country and when the tax rate on foreign investment income levied by the host country is constant (and therefore not influenced by the tax policy chosen by the capitalexporting home country).

It is useful to begin by describing the economy of the home country and the problem of choice is seen by a representative home country firm that has a foreign subsidiary. Aggregate production in the home country is determined by a production technology $F=F(K$, $L)$. The domestic labor supply $(L)$ will be taken as fixed, but the domestic capital stock $(K)$ must be regarded as endogenous, the difference between the exogenously given total national capital $(\bar{K})$ and the amount of capital transferred abroad to foreign subsidiaries $\left(K^{s}\right)$; i.e., $K=\bar{K}-K^{s}$. With constant returns to scale, each firm invests until its marginal product of capital is equal to the common value $F_{K}$. Firms pay tax at the rate $\theta$ on their domestic profits so the firms net marginal product of capital is $(1-\theta) F_{K}$.

The subsidiaries of the home country firms produce in the host country with a technology that in general differs from both their

5. Such an analysis could derive the optimal combination of tariffs and taxes in the more general framework of interdependence developed in the current paper. See Kemp [1966] and Jones [1967] for discussions of this problem without interdependence. 
technology at home and the technology of the local firms in the host country. We represent this subsidiary technology by $F^{s}=F^{s}\left(K^{s}, L^{s}\right)$ where $L^{s}$ is the host country labor employed by the subsidiaries. The subsidiaries earn pretax profits $F^{s}-w^{*} L^{s}$, where $w^{*}$ is the wage rate paid to all workers in the host country. The host country collects a tax at the rate $\theta^{*}$ on subsidiary profits. The after-tax profits available for division between the home country parent firm and the home country treasury are therefore $\left(1-\theta^{*}\right)\left(F^{s}-w^{*} L^{s}\right)$. At the margin, every subsidiary investment earns a net return $\left(1-\theta^{*}\right) F_{K}^{s}$.

The parent firm must pay an additional tax to the home country before its foreign investment income is available for distribution as gross dividends. It is useful to regard the home country tax as a combination of (1) a tax at rate $\theta^{s}$ on the subsidiary profit net of the host tax (i.e., a tax of $\theta^{s}\left(1-\theta^{*}\right) F_{K}^{s}$ on the marginal foreign investment income $F_{K}^{\prime}$ ) and (2) a credit at rate $\gamma$ for the tax paid to the host country (i.e., a credit of $\gamma \theta^{*} F_{K}^{s}$ on the marginal foreign investment income $F_{K}^{s}$ ). The net tax paid to the home country on the marginal investment is thus $\left[\theta^{s}\left(1-\theta^{*}\right)-\gamma \theta^{*}\right] F_{K^{*}}{ }^{6}$

Firms of the capital-exporting country invest at home and abroad until the net of tax rates of return are equal:

$$
(1-\theta) F_{K}=\left[\left(1-\theta^{s}\right)\left(1-\theta^{*}\right)+\gamma \theta^{*}\right] F_{K}^{s}
$$

The firms of the host country produce with a technology described by $F^{*}=F^{*}\left(K^{*}, L^{*}\right)$, where $K^{*}$ is fixed exogenously but $L^{*}$ is the difference between the exogenously fixed national labor supply $\left(\bar{L}^{*}\right)$ and the labor employed by the subsidiary firms $\left(L^{s}\right)$; i.e., $L^{*}=$ $L^{*}-L^{s}$. By assumption, these firms produce only in the host country. As a condition of production efficiency, the host country firms will pay a wage $w^{*}$ equal to the marginal product of labor $F_{L}^{*}$. Since host country workers are free to work for either the host country firms or the subsidiaries, the wage paid by the subsidiaries is also $w^{*}$ and their production efficiency requires $w^{*}=F_{L}^{s}$. Thus, labor market equilibrium implies that

$$
F_{L}^{*}\left(K^{*}, \bar{L}^{*}-L^{s}\right)=F_{L}^{s}\left(K^{s}, L^{s}\right) .
$$

This completes our description of the relevant economic behavior of the capital and labor markets. We can now turn to the optimization problem of the home country. The national income of the home country is the sum of the domestic income and the profits of its foreign subsidiaries net of host country taxes:

6. Note that this includes the special case of taxing foreign source income net of a credit for the foreign tax paid $\left(\theta^{s}-\theta^{*}\right) F_{K}^{s}$ by setting $\gamma=1-\theta^{s}$. 


$$
N=F\left(\bar{K}-K^{s}, L\right)+\left(1-\theta^{*}\right)\left(F^{s}-w^{*} L^{s}\right) .
$$

The home country selects $\theta^{s}$ and $\gamma$ to maximize $N$ with the knowledge that firms will respond by adjusting $K^{s}$ until (1.1) is satisfied and that the equilibrium of the host country labor market assures (1.2).

Before examining the general problem, consider first the case in which the demand for labor by the subsidiary firms is small enough (relative to the size of the host country labor force) to leave the host country wage rate $w^{*}$ unchanged. The first-order condition for a maximum of $N$ with respect to $\theta^{s}$ is then

$$
\frac{d N}{d \theta^{s}}=0
$$

or

$$
-F_{K} \frac{d K^{s}}{d \theta^{s}}+\left(1-\theta^{*}\right)\left[F_{K}^{s} \frac{d K^{s}}{d \theta^{s}}+F_{L}^{s} \frac{d L^{s}}{d \theta^{s}}-w^{*} \frac{d L^{s}}{d \theta^{s}}\right]=0
$$

Since $F_{L}^{s}=w^{*}$ is a condition of production efficiency for the subsidiary firms, equation (1.5) simplifies to

$$
\left[-F_{K}+\left(1-\theta^{*}\right) F_{K}^{s}\right] \frac{d K^{s}}{d \theta^{s}}=0
$$

Thus, the home country should choose its tax policies to make

$$
F_{K}=\left(1-\theta^{*}\right) F_{K}^{s}
$$

regardless of the magnitude of $d K^{s} / d \theta^{s} \neq 0$. Similarly, the first-order condition for a maximum of $N$ with respect to $\gamma$ implies that

$$
-F_{K} \frac{d K^{s}}{d \gamma}+\left(1-\theta^{*}\right)\left[F_{K}^{s} \frac{d K^{s}}{d \gamma}+F_{L}^{s} \frac{d L^{s}}{d \gamma}-w^{*} \frac{d L^{s}}{d \gamma}\right]=0
$$

It is clear from a comparison of (1.5) and (1.8) that this also implies condition (1.7).

Equation (1.1) implies that this condition is satisfied if the home country chooses $\theta^{s}=\theta$ and $\gamma=0$. This implies taxing subsidiary profits net of the tax paid to the host country at the same rate as domestic profits are taxed. The logic of this "full tax after deduction" method is clear. From the point of view of the home country, the nation's capital stock should be divided between home production and subsidiary production until the marginal product of capital to the nation is equal in both uses. Since foreign taxes are a cost to the nation, they should be subtracted in valuing the marginal product of capital of the subsidiary. In contrast, taxes levied by the home country 
are a cost to the firm but not the nation and must therefore be disregarded. The "full tax after deduction" method has been proposed in discussions of tax reform ${ }^{7}$ as a method of achieving "neutrality" in investment allocation. We have shown that it maximizes national income under a particular set of simple but restrictive assumptions. The "full tax after deduction" method is thus a useful benchmark against which to compare the taxes that are optimal in a more general framework.

In sections II and III we shall relax the assumption that the subsidiary firms are small enough to leave the host country wage unchanged. At this point we shall briefly examine the implication of dropping this assumption when the host country tax rate is constant. The first-order condition for maximization of $N$ with respect to $\theta^{s}$ now implies that

$-F_{K} \frac{d K^{s}}{d \theta^{s}}+\left(1-\theta^{*}\right)\left[F_{K}^{s} \frac{d K^{s}}{d \theta^{s}}+F_{L}^{s} \frac{d L^{s}}{d \theta^{s}}-w^{*} \frac{d L^{s}}{d \theta^{s}}-L^{s} \frac{d w^{*}}{d \theta^{s}}\right]=0$.

Although the subsidiary firms collectively raise $w^{*}$, each individual subsidiary still takes $w^{*}$ as exogenous and equates $F_{L}^{s}=w^{*}$. This allows (1.9) to be simplified in the same way as (1.5) and further implies that

$$
d w^{*}=F_{L K}^{s} d K^{s}+F_{L L}^{s} d L^{s} .
$$

Totally differentiating the equilibrium condition of the host country labor market (equation 1.2) implies that

$$
-F_{L L}^{*} d L^{s}=F_{L K}^{s} d K^{s}+F_{L L}^{s} d L^{s}
$$

and

$$
d L^{s}=\frac{-F_{L K}^{s} d K^{s}}{F_{L L}^{*}+F_{L L}^{s}}
$$

Substituting into (1.10) yields

$$
\begin{aligned}
d w^{*} & =F_{L K}^{s}\left[1-\frac{F_{L L}^{s}}{F_{L L}^{*}+F_{L L}^{s}}\right] d K^{s} \\
& =\frac{F_{L K}^{s} F_{L L}^{*}}{F_{L L}^{*}+F_{L L}^{s}} d K^{s} .
\end{aligned}
$$

Equation (1.9) can thus be written

7. See, e.g., Krause and Dam [1964] and Richman [1963]. 


$$
\left\{-F_{K}+\left(1-\theta^{*}\right)\left[F_{K}^{s}-\frac{L^{s} F_{L K}^{s} F_{L L}^{*}}{F_{L L}^{*}+F_{L L}^{s}}\right]\right\} \frac{d K^{s}}{d \theta^{s}}=0
$$

and, for any $d K^{s} / d \theta^{s} \neq 0$,

$$
F_{K}=\left(1-\theta^{*}\right)\left[F_{K}^{s}-\frac{L^{s} F_{L K}^{s} F_{L L}^{*}}{F_{L L}^{*}+F_{L L}^{s}}\right] .
$$

The first-order condition for a maximum of $N$ with respect to $\gamma$ also yields condition (1.15).

It is clear from (1.15) that the marginal product of subsidiary capital net of the foreign tax, $\left(1-\theta^{*}\right) F_{K}^{s}$, should exceed the marginal product of domestic capital $F_{K}$. This requires allocating a smaller fraction of the home country's capital stock to subsidiary production. This in turn entails a heavier tax on foreign source investment income than the "full tax after deduction" method. For example, with no credit $(\gamma=0)$ the optimal tax rate $\theta^{s}$ that satisfies (1.15) subject to (1.1) is the solution of

$$
\begin{gathered}
{\left[\frac{\left(1-\theta^{s}\right)\left(1-\theta^{*}\right)}{1-\theta}\right] F_{K}^{s}=\left(1-\theta^{*}\right)\left[F_{K}^{s}-\frac{L^{s} F_{L K}^{s} F_{L L}^{*}}{F_{L L}^{*}+F_{L L}^{s}}\right]} \\
\theta^{s}=\theta+\frac{1-\theta}{F_{K}^{s}}\left[\frac{L^{s} F_{L K}^{s} F_{L L}^{*}}{F_{L L}^{*}+F_{L L}^{s}}\right]
\end{gathered}
$$

The reason for this heavier optimal tax on net foreign profits is easy to understand. When the subsidiary firms in the aggregate raise the foreign wage that they must pay, they can increase their profits if they act as a monopsonist and reduce their collective demand for labor. Although the subsidiary firms cannot do this themselves, the home country can achieve the optimal reduction in the subsidiaries' demand for labor by a heavier tax on foreign investment. This explanation can alternatively be stated in terms of the subsidiaries as monopoly suppliers of capital. The increase in the host country wage implies a corresponding reduction in the marginal product of capital. Although the subsidiary firms individually cannot restrict the supply of capital to exploit this monopoly position, the home country can achieve this by a tax increase that reduces the capital export. ${ }^{8}$

In order to continue to use the "full tax after deduction" as a

8. This analysis is thus directly parallel to the case for a tariff in the theory of international trade. If the exporting country is a large supplier of the exported goods, a tariff can achieve the monopoly profit for the nation that individual export firms cannot achieve. See, for example, Baldwin [1952] for this analysis of the optimal tariff. The application to capital exports has been discussed by MacDougall [1960], Kemp [1962], and Jones [1967]. 
benchmark, the following sections of this paper will discuss both the general case and that in which the subsidiary firms account for a small enough part of the host economy so that their effect on local wage rates can be ignored. ${ }^{9}$ For simplicity, the tax credit (at rate $\gamma$ ), which we have just shown is optimally set equal to zero, will be ignored in the remaining analysis.

\section{TAX RATE INTERDEPENDENCE}

We are now ready to drop the simplifying assumption that only the capital-exporting country optimizes its tax rate $\left(\theta^{s}\right)$ while the capital-importing countries passively keep their own rate of tax on foreign investment $\left(\theta^{*}\right)$ unchanged. We specify instead that the capital-importing countries react to $\theta^{s}$ by setting the value of $\theta^{*}$ that maximizes their own national income conditional on $\theta^{s}$. We treat the capital importers as individual small countries each of which can take $\theta^{*}$ as given, assuming correctly that its choice of $\theta^{*}$ does not affect $\theta^{s} .10$ In contrast, the capital exporter is large and takes into account the effect of its choice of $\theta^{s}$ on the $\theta^{*}$ chosen by the capital importers. ${ }^{11}$

This specification converts the previous two-level optimization problem into a three-level problem. The capital-exporting country chooses $\theta^{s}$ to maximize its national income, taking into account the response to the capital-importing country that chooses $\theta^{*}$ to maximize its national income. In selecting $\theta^{*}$, the capital-importing country takes into account the response of the firms that invest in both countries. The capital-exporting country also recognizes the effect of its tax rate on the behavior of firms and understands that the capital-importing country does this as well.

It is useful to begin by restating the optimum condition of the

9. Comparing the optimum conditions of equations (1.7) and (1.15) shows that ignoring the effect of the subsidiaries on the host wage $w^{*}$ is equivalent to assuming that $F_{L L}^{*}$ is small relative to $F_{L L}^{s}$. Since the ratio of $F_{L L}^{*}$ to $F_{L L}^{s}$ is of the same order as $L^{*} / L^{*}$, ignoring the change in $w^{*}$ is appropriate if $L^{s}$ is small relative to $L^{*}$.

10. We implicitly treat all of the capital-importing countries as identical; each therefore chooses the same $\theta^{*}$. We could generalize by making the technologies differ among the capital importers and thus obtain a different $\theta^{*}$ for each. The capital exporter would then respond to a suitably weighted average. No new insights would result from such a generalization.

11. We are, in the terminology of the bilateral monopoly problem, assuming that the capital-importing countries behave according to the Cournot reaction curve and that the capital-exporting country knows that this behavior will occur. Therefore, a Stackelberg equilibrium is reached, with the capital-exporting country acting as the leader. Hamada [1966] considers some other duopoly solutions for the related case of a pure capital transfer. 
capital-exporting country in this more general situation. In place of equation (1.6) we obtain

$$
\begin{aligned}
& {\left[F_{K}-\left(1-\theta^{*}\right)\left(F_{K}^{s}-L^{s} \frac{d w^{*}}{d K^{s}}\right)\right] \frac{d K^{s}}{d \theta^{s}} } \\
= & \left.-\left(\frac{d \theta^{*}}{d \theta^{s}}\right)\right)\left\{F^{s}-w^{*} L^{s}+\left[F_{K}-\left(1-\theta^{*}\right)\left(F_{K}^{s}-L^{s} \frac{d w^{*}}{d K^{s}}\right)\right] \frac{d K^{s}}{d \theta^{*}}\right\} .
\end{aligned}
$$

The equilibrium condition for the international firms, i.e.,

$$
(1-\theta) F_{K}=\left(1-\theta^{s}\right)\left(1-\theta^{*}\right) F_{K}^{s},
$$

implies that (2.1) can be rewritten as

$$
\begin{aligned}
{\left[\frac{\theta-\theta^{s}}{1-\theta^{s}} F_{K}+\right.} & \left.\left(1-\theta^{*}\right) L^{s} \frac{d w^{*}}{d K^{s}}\right] \frac{d K^{s}}{d \theta^{s}}=-\left(\frac{d \theta^{*}}{d \theta^{s}}\right)\left\{F^{s}-w^{*} L^{s}\right. \\
+ & {\left.\left[\frac{\theta-\theta^{s}}{1-\theta^{s}} F_{K}+\left(1-\theta^{*}\right) L^{s} \frac{d w^{*}}{d K^{s}}\right] \frac{d K^{s}}{d \theta^{s}}\left(\frac{1-\theta^{s}}{1-\theta^{*}}\right)\right\} }
\end{aligned}
$$

or, rearranging and using (1.13), as

$$
\begin{aligned}
{\left[\frac{\theta-\theta^{\mathrm{s}}}{1-\theta^{s}} F_{K}+\left(1-\theta^{*}\right) \frac{L^{s} F_{L K}^{s} F_{L L}^{*}}{F_{L L}^{*}+F_{L L}^{s}}\right] \frac{d K^{s}}{d \theta^{s}} } & \left(1+\frac{d \theta^{*}}{d \theta^{s}}\left(\frac{1-\theta^{s}}{1-\theta^{*}}\right)\right) \\
= & -\left(\frac{d \theta^{*}}{d \theta^{s}}\right)\left[F^{s}-w^{*} L^{s}\right] .
\end{aligned}
$$

Equation (2.4) shows that the size of the optimal $\theta^{s}$ relative to the given domestic tax rate $\theta$ depends on the sign of $d \theta^{*} / d \theta^{s}$. This dependence is shown more explicitly by rewriting (2.4) as

$$
\begin{aligned}
\theta^{s}=\theta+ & \frac{1-\theta}{F_{K}^{s}}\left[\frac{L^{s} F_{L K}^{s} F_{L L}^{*}}{F_{L L}^{*}+F_{L L}^{s}}\right] \\
& +\left(\frac{1-\theta}{1-\theta^{*}}\right) \frac{1}{F_{K}^{s}}\left\{\frac{d \theta^{*}}{d \theta^{s}}\left[F^{s}-w^{*} L^{s}\right] /\left[1+\frac{d \theta^{*}}{d \theta^{s}}\left(\frac{1-\theta^{s}}{1-\theta^{*}}\right)\right] \frac{d K^{s}}{d \theta^{s}}\right\} .
\end{aligned}
$$

Equation (2.5) demonstrates how the divergence of the optimal tax on foreign source income from the tax on home country domestic income results from the two factors we are discussing: the tendency of the home country's tax policy to influence wages faced in the host country and to influence host country tax policy.

Specifically, the second term on the right side of (2.5) is the host country wage factor, which was derived in the previous section (see (1.17)). Since host country wages are always reduced by a restriction 
of the capital transfer, this term is unambiguously positive, tending to make the optimal tax on foreign source income greater than the tax on domestic income.

Having isolated the host country wage factor, we know that the last term of (2.5) is the host country tax effect. That is, dropping the assumption of a fixed host country tax provides a further reason for the optimal tax on foreign source income to differ from the domestic tax. Since $F^{s}-w^{*} L^{s}$ and $F_{K}^{s}$ are positive while $d K^{s} / d \theta^{s}$ is negative, the sign of this term is given by the sign of $-\left(d \theta^{*} / d \theta^{s}\right) .{ }^{12}$ The economic reason for this is clear. If an increase in $\theta^{s}$ causes a decrease in $\theta^{*}$, the home country should raise $\theta^{s}$ in order to benefit from a lower rate of foreign taxation.

If an increase in the foreign source income tax levied by the capital-exporting country induces a decrease in the tax levied by the capital-importing country (i.e., $d \theta^{*} / d \theta^{s}<0$ ), both the host country wage factor and the host country tax factor operate in the same direction. Therefore, foreign source income should be treated less favorably than domestic income. In fact, $\theta^{s}$ should be even larger than the value that would be optimal with a fixed $\theta^{*}$. Conversely, if an increase in the tax on foreign source income levied by the capital-exporting country causes an increase in the tax levied by the capitalimporting country (i.e., $\left.d \theta^{*} / d \theta^{s}>0\right)$, then the sign of $\left(\theta-\theta^{s}\right)$ is ambiguous. Whether the home country tax system should favor foreign source income over domestic income depends on whether an increase in the home country tax on foreign source income causes a sufficiently large decline in foreign wages to compensate for the increased tax imposed by the foreign country. The crucial questions for the capital-exporting country are the sign and (only if the sign is positive) the magnitude of $d \theta^{*} / d \theta^{s}$.

To assess the response of $\theta^{*}$ to $\theta^{s}$, we must examine the optimization problem of the host country. The national income of the capital-importing country is the sum of its own production $\left(F^{*}\right)$ and the production of the subsidiary firms $\left(F^{s}\right)$ minus the net-of-tax profits that can be returned to the capital-exporting country:

$$
N^{*}=F^{*}\left(\bar{K}^{*}, \bar{L}^{*}-L^{s}\right)+F^{s}\left(K^{s}, L^{s}\right)-\left(1-\theta^{*}\right) F_{K}^{s} K^{s} .
$$

Totally differentiating (2.6) with respect to $\theta^{*}$ yields the first-order condition:

12. This uses the stability condition $d\left\{\left(1-\theta^{*}\right)\left(1-\theta^{s}\right)\right\} / d \theta^{s}<0$. If this were not true, the capital-exporting country could benefit indefinitely by raising its tax rate. 
(2.7) $-F_{L}^{*} \frac{d L^{s}}{d \theta^{*}}+F_{L}^{s} \frac{d L^{s}}{d \theta^{*}}+F_{K}^{s} \frac{d K^{s}}{d \theta^{*}}-\left(1-\theta^{*}\right) F_{K} \frac{d K^{s}}{d \theta^{*}}$

$$
-\left(1-\theta^{*}\right) K^{s} F_{K K}^{s} \frac{d K^{s}}{d \theta^{*}}-\left(1-\theta^{*}\right) K^{s} F_{K L}^{s} \frac{d L^{s}}{d \theta^{*}}+F_{K}^{s} K^{s}=0 .
$$

We can simplify this equation by using the condition for labor market equilibrium in the host country:

$$
F_{L}^{*}\left(K^{*}, L^{*}-L^{s}\right)=F_{L}^{s}\left(K^{s}, L^{s}\right) .
$$

Note first that this implies immediately that the first two terms of (2.7) sum to zero and can be eliminated. Totally differentiating (2.8) yields

$$
-F_{L L}^{*} d L^{s}=F_{L L}^{s} d L^{s}+F_{L K}^{s} d K^{s}
$$

or

$$
d L^{s}=-\left[F_{L K}^{s} /\left(F_{L L}^{s}+F_{L L}^{*}\right)\right] d K^{s} .
$$

Using (2.10) to replace $d L^{s} / d \theta^{s}$ in (2.7) by the corresponding term in $d K^{s} / d \theta^{s}$ permits $(2.7)$ to be written as

$$
\left\{\theta^{*} F_{K}^{s}+\left(1-\theta^{*}\right) K^{s}\left[\frac{\left(F_{K L}^{s}\right)^{2}}{F_{L L}^{*}+F_{L L}^{s}}-F_{K K}^{s}\right]\right\} \frac{d K^{s}}{d \theta^{*}}+F_{K}^{s} K^{s}=0
$$

Since constant returns to scale implies that $\left(F_{K L}^{s}\right)^{2}=F_{L L}^{s} F_{K K}^{s},(2.11)$ simplifies further to

$$
\left[\theta^{*}-\left(1-\theta^{*}\right) \frac{K^{s} F_{K K}^{s}}{F_{K}^{s}} Q\right] \frac{d K^{s}}{d \theta^{*}}+K^{s}=0,
$$

where

$$
Q=F_{L L}^{*} /\left(F_{L L}^{*}+F_{L L}^{s}\right) .
$$

Instead of analyzing (2.12) any further, it is useful to develop an explicit expression for $d K^{s} / d \theta^{*}$. We begin with the international firms' first-order condition for capital allocation:

$$
\left(1-\theta^{*}\right)\left(1-\theta^{s}\right) F_{K}^{s}\left(K^{s}, L^{s}\right)=(1-\theta) F_{K}\left(\bar{K}-K^{s}, L\right)
$$

and totally differentiate to obtain

$$
\begin{aligned}
\left(1-\theta^{*}\right)\left(1-\theta^{s}\right)\left[F_{K K}^{s} d K^{s}+F_{K L}^{s} d L^{s}\right]- & \left(1-\theta^{s}\right) F_{K}^{s} d \theta^{*} \\
& =-(1-\theta) F_{K K} d K^{s}
\end{aligned}
$$

Using equation (2.10) to substitute for $d L^{s}$ and taking into account that $\left(F_{K L}^{\mathrm{s}}\right)^{2}=F_{L L}^{s} F_{K K}^{\mathrm{s}}$, we can rewrite $(2.15)$ as 


$$
\begin{aligned}
\frac{d K^{s}}{d \theta^{*}} & =\frac{\left(1-\theta^{s}\right) F_{K}^{s}}{\left(1-\theta^{*}\right)\left(1-\theta^{s}\right) F_{K K}^{s} Q+(1-\theta) F_{K K}} \\
& =\left\{\left(1-\theta^{*}\right) Q \frac{F_{K K}^{s}}{F_{K}^{s}}+\frac{(1-\theta) F_{K K}}{\left(1-\theta^{s}\right) F_{K}^{s}}\right\}^{-1} .
\end{aligned}
$$

Since (2.14) implies that $\left(1-\theta^{s}\right) F_{K}^{s}=\left(1-\theta^{*}\right)^{-1}(1-\theta) F_{K}$, this can be expressed more symmetrically as

$$
\frac{d K^{s}}{d \theta^{*}}=\left(1-\theta^{*}\right)^{-1}\left\{Q \frac{F_{K K}^{s}}{F_{K}^{s}}+\frac{F_{K K}}{F_{K}}\right\}^{-1} .
$$

Combining (2.12) and (2.17) yields

$$
\frac{\left[\theta^{*} /\left(1-\theta^{*}\right)\right]-K^{s} F_{K K}^{s} Q / F_{K}^{s}}{Q F_{K K}^{s} / F_{K}^{s}+F_{K K} / F_{K}}=-K^{s}
$$

or

$$
\frac{\theta^{*}}{1-\theta^{*}}=-\frac{K F_{K K}}{F_{K}} \cdot \frac{K^{s}}{K}
$$

For any constant returns to scale technology, $-K F_{K K} / F_{K}=(1-\alpha) / \sigma$, where $\alpha=F_{K} K / F$ is the capital share and $\sigma$ is the elasticity of substitution; of course, $\alpha$ and $\sigma$ are local values and not necessarily constants. Since $K=\bar{K}-K^{s}$, we can write the host country's optimum condition as

$$
\frac{\theta^{*}}{1-\theta^{*}}=\frac{1-\alpha}{\sigma} \frac{K^{s}}{\bar{K}-K^{s}} .
$$

Since a Cobb-Douglas technology is the only case in which $\alpha$ remains constant when $K^{s}$ and therefore $K$ changes, it is simplest to consider its implications first. With $\alpha$ a constant (and $\sigma=1$ ), equation (2.20) implies unambiguously that $\theta^{*}$ is an increasing function of $K^{s}$. A greater extent of capital exporting in the home country induces a higher optimal tax rate in the host country. Since a higher tax on foreign source investment income $\left(\theta^{s}\right)$ discourages capital exports, it follows immediately that a higher value of $\theta^{s}$ induces a lower value of $\theta^{*}$. As we emphasized above, this implies that the capital-exporting country should tax foreign source investment income more heavily than domestic investment income, i.e., that the optimal value of $\theta^{s}$ exceeds $\theta$. We have thus proven the following:

PROPOSITION 1. If the capital-exporting firms have a Cobb-Douglas technology in home production, the capital-exporting country 
should tax foreign source investment income more heavily than domestic investment income.

This proposition can be generalized to any plausible constant elasticity of substitution technology in the capital-exporting country. ${ }^{13}$ Equation (2.20) can be rewritten as

$$
\sigma\left(\frac{\theta^{*}}{1-\theta^{*}}\right)=\left(1-\frac{K F_{K}}{F}\right)\left(\frac{\bar{K}-K}{K}\right) \text {. }
$$

The right-hand side is now a function of $K$ only. Since $\sigma$ is a constant, the left-hand side is an increasing function of $\theta^{*}$; for convenience we denote it by $Z$. We can now examine $d Z / d K$. If $d Z / d K<0$, an increase in $K$ implies a decrease in $\theta^{*}$. But since $K=\bar{K}-K^{s}$ and $d K^{s} / d \theta^{s}<$ 0 , an increase in $\theta^{s}$ implies an increase in $K$. Thus, $d Z / d K<0$ implies that $d \theta^{*} / d \theta^{s}=\left(d \theta^{*} / d K\right)\left(d K / d \theta^{s}\right)<0$. The result established for the Cobb-Douglas technology is therefore valid for any constant elasticity of substitution technology if $d Z / d K<0$.

From equation (2.21)

$$
Z=\frac{\bar{K}}{K}-1-\frac{\bar{K} F_{K}}{F}+\frac{K F_{K}}{F},
$$

and therefore

$$
\frac{d Z}{d K}=\frac{-\bar{K}}{K^{2}}-\frac{\bar{K} F_{K K}}{F}+\frac{\bar{K} F_{K}^{2}}{F^{2}}+\frac{K F_{K K}}{F}+\frac{F_{K}}{F}-\frac{K F_{K}^{2}}{F^{2}}
$$

By substituting $-K F_{K K} / F_{K}=(1-\alpha) / \sigma$ and $K F_{K} / F=\alpha$, we obtain

$\frac{K^{2}}{\bar{K}} \frac{d Z}{d K}=\frac{(\bar{K}-K)}{\bar{K}} \cdot \frac{\alpha(1-\alpha)}{\sigma}+\frac{(\bar{K}-K)}{\bar{K}} \alpha^{2}-\frac{\bar{K}-K}{\bar{K}}-\frac{K(1-\alpha)}{\bar{K}}$.

Thus, $d Z / d K<0$ if

$$
\frac{\bar{K}-K}{\bar{K}}\left\{\frac{\alpha(1-\alpha)}{\sigma}+\alpha^{2}-1\right\}<\frac{K}{\bar{K}}(1-\alpha)
$$

or

$$
\frac{\alpha}{\sigma}-(1+\alpha)<\frac{K}{\bar{K}-K}
$$

13. Note that the nature of the production functions of the subsidiaries and of the host country firms are irrelevant. 
But, from $(2.20) K /(\bar{K}-K)=[(1-\alpha) / \sigma]\left[\left(1-\theta^{*}\right) / \theta^{*}\right]$. Inequality (2.26) is therefore equivalent to

$$
\frac{\alpha}{\sigma}-(1+\alpha)<\frac{1-\alpha}{\sigma} \cdot \frac{1-\theta^{*}}{\theta^{*}}
$$

or

$$
\frac{1-\sigma(1+\alpha)}{1-\alpha}<\frac{1}{\theta^{*}}
$$

Since $\theta^{*}<1$, this will be satisfied wherever

$$
\alpha<\sigma(1+\alpha) .
$$

Although this could in principle be false if the elasticity of substitution were low enough, it is true for any empirically reasonable value of $\sigma$. Inequality (2.29) therefore implies that $d Z / d K<0$ and thus $d \theta^{*} / d K$ $<0$. An increase in $\theta^{s}$ by reducing capital exports and increasing $K$ thus lowers the host country's optimal tax rate: $d \theta^{*} / d \theta^{s}<0$. From this it follows that the capital-exporting country's optimal tax on foreign source investment income exceeds the tax on domestic income. We thus have proved the following:

PROPOSITION 2. If the capital-exporting firms have a constant elasticity of substitution production function with $\sigma>\alpha /(1+\alpha)$, the capital-exporting country should tax foreign source income more heavily than domestic investment income.

If the home country's foreign investment is sufficiently small that changes in its tax rate have no effect on host country wages, the second term in (2.5) is zero. The home country still has an incentive to favor domestic investment over foreign investment with its tax policy. ${ }^{14}$

\section{ForEIGN BorRowing}

Firms that invest abroad frequently also borrow in the host country. In general, the amount of borrowing that a firm does in a foreign country increases with the amount of its equity investment there. ${ }^{15}$ The reason for this association between equity investment

14. To obtain this result, it is, of course, necessary that $d \theta^{*} / d \theta^{s}$ be negative. To see that Propositions 1 and 2 continue to hold, it is necessary to observe that $Q$, given by (2.13), equals zero when the host country wage is fixed. Therefore, by (2.18) the host country tax response (2.19) is the same as when the host country wage is affected.

15. Hartman [1976] provides evidence that on average each dollar of new equity capital transferred from the United States to direct investment outside North America is accompanied by borrowing an additional two dollars. Retained profits of subsidiaries also contribute to the finance of such foreign investment. 
and host country borrowing presumably reflects the impact of local equity investment on the risk perceptions of both borrowers and lenders.

The real rate of interest that firms pay for such borrowed funds is clearly less than the marginal product of investment in the subsidiary firms. ${ }^{16}$ This implies that each dollar of equity investment transferred from the home country earns more for the home country than the subsidiaries' marginal product of investment net of host country taxes. It is natural to ask: Does this "leverage gain" imply that foreign source investment income should be taxed more lightly than would be optimal if there were no borrowing?

Consider the case in which the "full taxation after deduction" rule would be optimal if the foreign investment were financed only by equity, i.e., the case in which the host tax rate $\left(\theta^{*}\right)$ and the host wage rate $\left(w^{*}\right)$ are independent of the home country tax rate $\left(\theta^{S}\right)$. Assume for the moment that everyone in the capital-exporting country is risk-neutral with respect to the amount involved in the foreign investment. If the home country applies the "full taxation after deduction" rule, the firms will invest abroad until the net marginal product of their equity investment abroad-including the leverage gain but net of the host country tax-is equal to the marginal product of equity in domestic investment. It is clear that this allocation of capital is also optimal from the home country's point of view. The leverage gain on overseas investment increases the optimal amount of such investment but does not alter the marginal optimality condition that marginal domestic and foreign investment should be equally productive to the home country. With risk neutrality the optimality of the "full taxation after deduction" rule is unaffected by borrowing.

This conclusion is unchanged when shareholders in the home country are risk-averse if the government (i.e., the taxpayers in general) has the same attitude about risky investments. If shareholders are risk-averse, subsidiary firms will invest and borrow abroad until the marginal net return on their leveraged equity - after adjusting for the risk of foreign investment and borrowing-is equal to the marginal risk-adjusted return that they receive at home. The "full taxation after deduction" rule thus remains optimal with risk aversion even if the tax rules affect the extent of foreign borrowing.

16. It is optimal for firms to borrow until the marginal cost of debt capital equals the marginal product of the investment. Since the interest rate is an increasing function of the debt-equity ratio, the marginal cost of debt exceeds the interest rate. See Feldstein, Green, and Sheshinski [1979] for an analysis of the optimal debt-equity rates in a closed economy. 
Note finally that this conclusion ceases to hold if the government has a different risk aversion than the shareholders. Consider, for example, the case in which shareholders are risk-averse, while the government is not risk-averse with respect to its tax revenue. ${ }^{17}$ If a lower tax rate on foreign source investment income increases both equity investment abroad and foreign borrowing, this lower tax rate raises the "leverage gain" to the capital-exporting country. If the share of the gain that accrues to the home country tax revenue is not discounted for its increased riskiness, this increase in borrowing represents a net national gain.

\section{CONCLUSION}

As we noted at the beginning of this paper, we are well aware of the limitations of our simplified model. We believe, however, that we have provided a framework for analyzing international taxation in a world in which small countries adjust their tax rates in response to the policies of large countries. The current analysis should be extended to incorporate the role of trade, the use of portfolio investment and the multinational character of investment and tax competitiveness. The rapid growth of international investment points clearly to the potential gains from a better understanding of these issues.

HARVARD UNIVERSITY AND

NATIONAL BUREAU OF ECONOMIC RESEARCH

\section{REFERENCES}

Baldwin, Robert E., "The New Welfare Economics and Gains in International Trade," this Journal, LXVI (Feb. 1952), 91-101.

Feldstein, Martin, Jerry Green, and Eytan Sheshinski, "Corporate Financial Policy and Taxation in a Growing Economy," this Journal, XCIII (Aug. 1979), 41132.

Hamada, Koichi, "Strategic Aspects of Taxation of Foreign Investment Income," this Journal, LXXX (Aug. 1966), 361-75.

Hartman, David G., "Taxation of Foreign Source Investment Income," Ph.D. thesis, Harvard University, 1976.

Horst, Thomas, "American Taxation of Multinational Firms," American Economic Review, LXVII (June 1977), 376-89.

Hufbauer, Gary C. et al., U. S. Taxation of American Business Abroad: An Exchange of Views, AEI-Hoover Policy Study 16, September 1975 (Washington, D. C.: American Enterprise Institute for Public Policy Research, 1975).

Jones, Ronald W., "International Capital Movements and the Theory of Tariffs and Trade," this Journal, LXXXI (Feb. 1967), 1-38.

17. The government might regard its ability to pool the tax revenues from many activities as effectively eliminating the risk on each such activity from the point of view of the taxpayers as a whole. 
Kemp, Murray C., "Foreign Investment and the National Advantage," Economic Record, XXXVIII (March 1962), 56-62.

Krause, Lawrence B., and Kenneth W. Dam, Federal Tax Treatment of Foreign In. come (Washington, D. C.: The Brookings Institution, 1964).

MacDougall, G. D. A., "The Benefits and Costs of Private Investment from Abroad: A Theoretical Approach," Economic Record, XXXVI (1960), 13-35.

Musgrave, Peggy B., United States Taxation of Foreign Investment Income: Issues and Arguments (Cambridge, Mass.: Harvard Law School International Tax Program, 1969).

Direct Investment Abroad and the Multinationals: Effects on the United States Economy, Senate Foreign Relations Committee Print, 94th congress, 1st session, 1975.

Richman, Peggy Brewer, Taxation of Foreign Investment Income: An Economic Analysis (Baltimore: The Johns Hopkins Press, 1963). 